\title{
Mitteilungen der Österreichischen Schmerzgesellschaft
}

Sehr geehrte Damen und Herren, liebe KollegInnen,

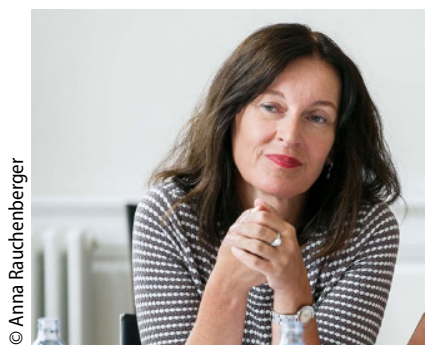

Schmerzpatientinnen und -patienten brauchen ÄrztInnen, die kompetent und auf dem letzten Stand der Wissenschaft für die beste Behandlung sorgen können. Die Österreichische Schmerzgesellschaft hat sich daher entschlossen, 2021 mit einer Schmerzakademie zu starten und führt mittlerweile eine ganze Reihe von Fortbildungen durch. Unter anderem bieten wir Schmerzdiplomkurse in Modulform an, aber auch zahlreiche Online-Fortbildungen - unsere sogenannten Pain Updates. Im Herbst wird es gleich drei an der Zahl geben. Das Kursangebot richtet sich an Ärztinnen und Ärzte der Allgemeinmedizin als auch an KollegInnen aus anderen Fachrichtungen, die mit SchmerzpatientInnen zu tun haben. Das gilt natürlich insbesondere für jene Ärztinnen und Ärzte, die in schmerztherapeutischen Einrichtungen tätig sind oder beabsichtigen, in einer solchen Einrichtung tätig zu werden. Werfen Sie einen Blick auf unsere Website www.oesg.at - hier ist das gesamte Programm ersichtlich und wir freuen uns, wenn Sie bei einer der nächsten Fortbildungen dabei sind.

Neben diesem großen Fortbildungsprojekt werden wir nach langer Vorbereitungs- und Verhandlungszeit jetzt mit der Merkur Versicherung die Initiative Beweg Dich starten. Bewegung hilft nicht nur effektiv gegen Schmerzen, regelmäßiger Sport bietet auch einen Anti-Schmerz-Bonus. Daher sind Sportlerlnnen gegenüber Nichtsportlerlnnen zwar nicht weniger schmerzempfindlich, aber dafür schmerztoleranter. Ein Ansatz, der neue Denkrichtungen auch für chronische SchmerzpatientInnen eröffnet: Sport und

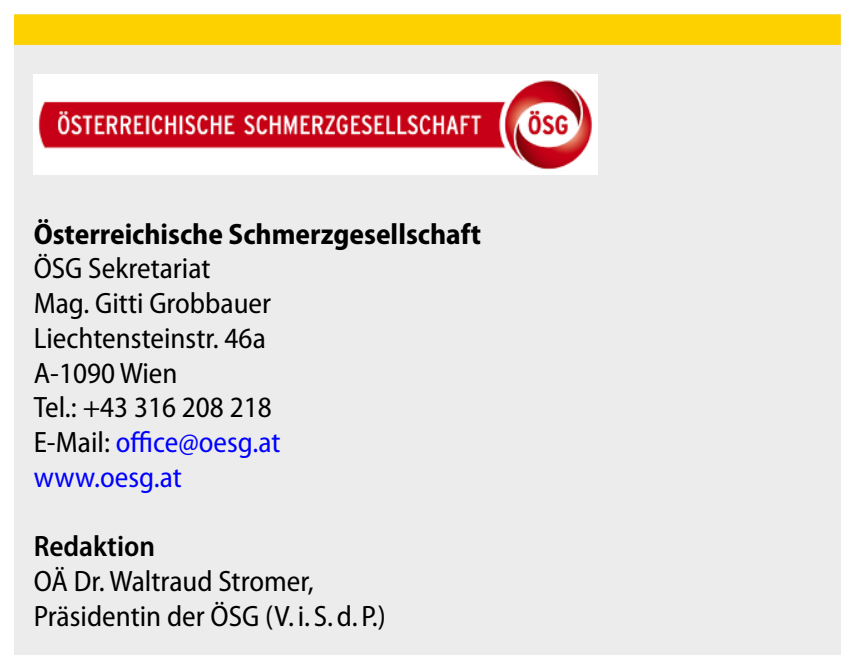

Bewegung als therapeutische Maßnahme. Dieser Ansatz soll über eine Plakatkampagne öffentlich kommuniziert werden und damit breites Bewusstsein schaffen. Wir hoffen, vor allem unsere ÖSGMitglieder in den Schmerzambulanzen, Schmerzzenten und Ordinationen als Unterstützerlnnen der Kampagne zu gewinnen. Der Start ist mit Spätherbst geplant.

Ihre

OÄ Dr. Waltraud Stromer

Präsidentin der Österreichischen Schmerzgesellschaft

Schmerz 2021 35:377

https://doi.org/10.1007/s00482-021-00595-w

(c) Springer Medizin Verlag GmbH, ein Teil von Springer Nature 2021

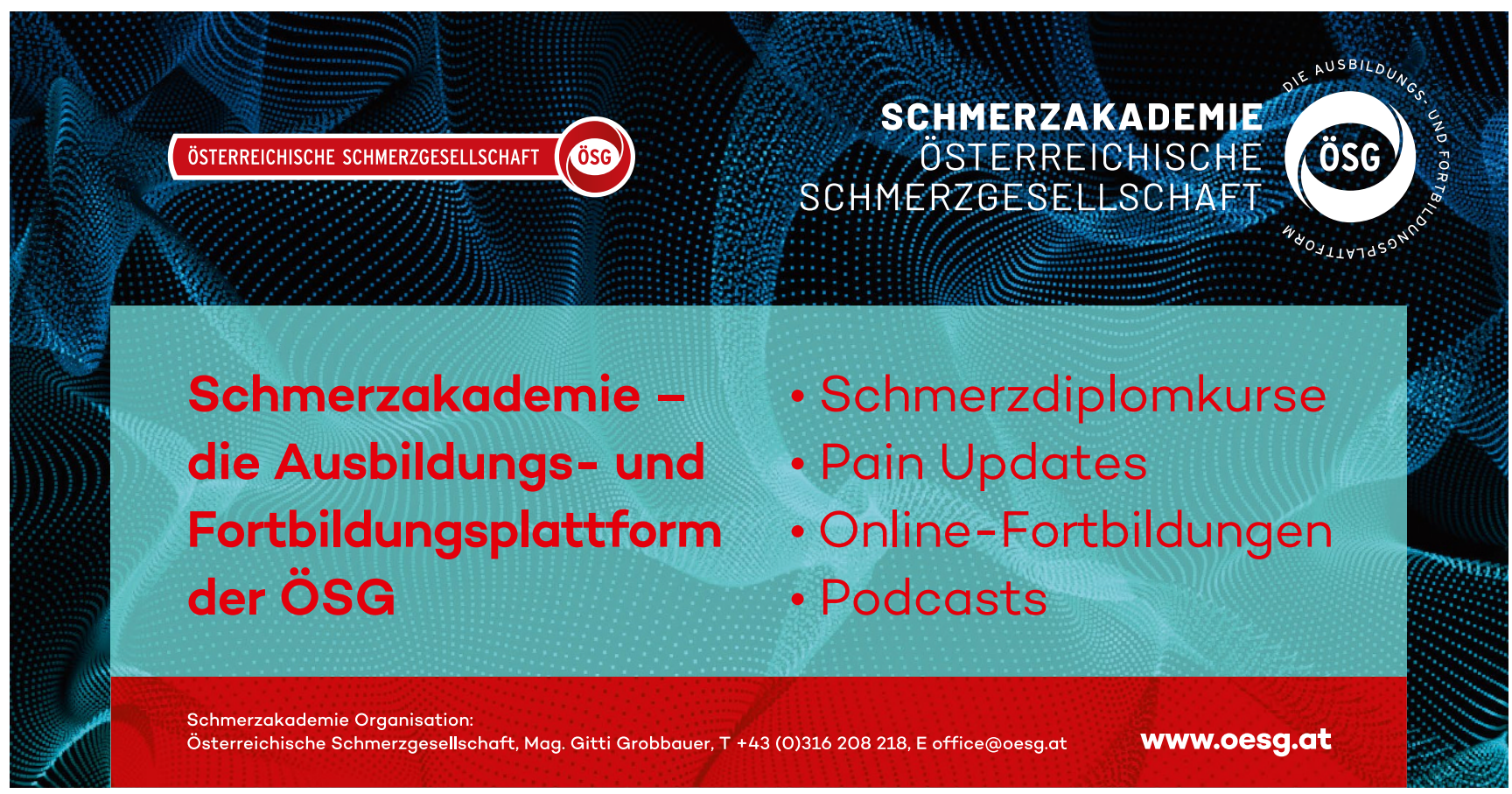

